\title{
A complete extracorporeal circulation free approach to patients with univentricular hearts provides superior early outcomes
}

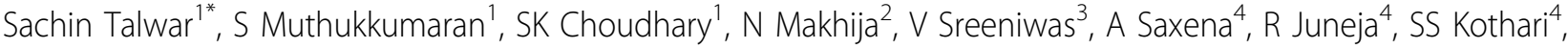 \\ B Airan ${ }^{1}$
}

From 23rd World Congress of the World Society of Cardio-Thoracic Surgeons

Split, Croatia. 12-15 September 2013

\section{Background}

Although there are small reported series of patients undergoing the Extracardiac Total cavopulmonary connection without cardiopulmonary bypass, there is paucity of data comparing the results of the two.

\section{Methods}

Between February 2012 and February 2013, 27 patients undergoing Total cavopulmonary connection without cardiopulmonary bypass (off-pump group) were compared with propensity score matched 27 patients undergoing Total cavopulmonary connection on cardiopulmonary bypass (on-pump group). Outcome parameters studied were inotropic score, time to extubation, intensive care unit stay, mediastinal drainage in the intensive care unit, daily pleural drainage, time to removal of chest tubes, hospital stay and saturation at discharge.

\section{Results}

There was one early death in each group. No patient required conversion from off pump to cardiopulmonary bypass. The inotropic score $(6.1 \pm 5.91$ versus $10.1 \pm 6.80$, $\mathrm{p}=0.03)$, time to extubation $(8.7 \pm 6.95$ versus $10.31 \pm$ 8.69hours, $\mathrm{p}=.03$ ), mediastinal drainage in intensive care unit $(611.9 \pm 341.4$ versus $922.2 \pm 145.6 \mathrm{ml}, \mathrm{p}=0.03)$ and intensive care unit stay $(1.6 \pm 0.58$ versus $2.9 \pm 1.37$ days, $\mathrm{p}<0.001)$ were significantly less in off pump group as compared to on-pump group and saturation at discharge (99.7 \pm 0.60 versus $98.6 \pm 2.13, \mathrm{p}=0.026)$ was higher in the off-pump group. However the daily pleural drainage
$(125 \pm 61.7 .2$ versus $150 \pm 103.4 \mathrm{ml}, \mathrm{p}=0.7)$, time to removal of chest tubes $(12.69 \pm 7.1$ versus $15.44 \pm 19.26$ days, $\mathrm{p}=0.45)$ and the total hospital stay $(14.23 \pm 7.4$ versus $18.89 \pm 19.9$ days, $\mathrm{p}=0.22$ ) were no different. There were substantial savings in costs in patients undergoing off-pump procedure.

\section{Conclusion}

Extracardiac Total cavopulmonary connection without cardiopulmonary bypass is easy to perform, is cost effective, and is associated with superior early post-operative outcomes. With appropriate modifications, this operation can be performed in almost all morphological subsets of patients who do not need an associated intracardiac procedure.

\section{Authors' details}

'Department of Cardiothoracic and Vascular Surgery, All India Institute of Medical Sciences, New Delhi -110029, India. ${ }^{2}$ Cardiothoracic Sciences Centre, All India Institute of Medical Sciences, New Delhi-110029, India, New Delhi, India. ${ }^{3}$ Department of Biostatistics All India Institute of Medical Sciences, New Delhi-110029, India, New Delhi, India. ${ }^{4}$ All India Institute of Medical Sciences, New Delhi-110029, India, New Delhi, India.

Published: 11 September 2013

doi:10.1186/1749-8090-8-S1-0313

Cite this article as: Talwar et al:: A complete extracorporeal circulation free approach to patients with univentricular hearts provides superior early outcomes. Journal of Cardiothoracic Surgery 2013 8(Suppl 1):O313.

\footnotetext{
* Correspondence: sachintalwar@hotmail.com

'Department of Cardiothoracic and Vascular Surgery, All India Institute of Medical Sciences, New Delhi -110029, India

Full list of author information is available at the end of the article
}

(c) 2013 Talwar et al; licensee BioMed Central Ltd. This is an Open Access article distributed under the terms of the Creative Commons 